\title{
INTEGRAL EVALUATION OF THE ECONOMIC ACTIVITY, EMPLOYMENT AND UNEMPLOYMENT IN THE REGIONS OF BULGARIA
}

\author{
Y. Hristoskov* \\ Faculty “Economic and Social Sciences”, Plovdiv University “Paisii Hilendarski”, Plfvdiv, Bulgaria
}

\begin{abstract}
The purpose of this article is to identify the trends and territorial differences in the economic activity, employment and unemployment, and on this grounds to recommend solutions for overcoming or reduction of the severity of the issues. The study explores the condition and disparities in the labor potential of the regions in the context of the acknowledged and ever deepening demographic crisis in Bulgaria. The object of analysis is the dynamics of the economic activity, employment and unemployment at national and regional level, represented by one summarizing indicator. The integral indicator Economically Active and Employed Population (EAEP), developed by the author, is applied in order to trace the dynamics at national level and to assess the implementation of the set national employment targets under the Europe 2020 program. A modified version of this indicator $\left(\operatorname{EAEP}_{(\mathrm{m})}\right)$ is also applied, in order to assess the territorial fluctuations in the economic activity, employment and unemployment at the NUTS-2 level. The values of this indicator obtained for each region are compared to already previously set benchmarks. On this basis, the risk regions are identified and solutions are proposed to reduce the problems.
\end{abstract}

Key words: labor potential, regional disparities, nintegral indicator, national goals, regional bench marks

The analysis of the working and the economically active population, the employed and the unemployed, as well as of the respective coefficients of the economic activity, employment and unemployment, demonstrates that their dynamics at national and regional levels depend to a great extent on the demographic basis and the changes in it, and even more so on the coefficient of demographic replacement. During the separate (independent) analysis of these indicators of the labor market situation, are practically possible not only differences in their dynamics but also certain contradictory tendencies. For instance, the economic activity may be increasing, while employment and unemployment may be declining; or the number of people employed can be decreasing, but also unemployment is showing a downward trend (as is the case with the Northwest region). It is also possible to reduce unemployment without increasing

\footnotetext{
*Correspondence to: Prof. Dr. Yordan Hristoskov, Plovdiv University Paisii Hilendarski, Faculty

"Economic and Social Sciences", E-mail:

jhristoskov@yahoo.com,Tel: +359888951907
}

employment. These statistical paradoxes are due to the different rates of growth/ decline of the working-age population, to the economically active population and other demographic features, especially when analyzing indicators in long-term statistical lines. The process of transfusion of contingents of persons outside the workforce (people with disabilities, students, discouraged workers, pensioners, those working in the gray sector) towards formal employment and unemployment, and vice-versa - the withdrawal of labor force contingents from the group of economically inactive persons in a particular conjunctural situation of the labor market.

In order to overcome the shortcomings of the independent (self-contained) analysis of the economic activity, employment and unemployment, it is necessary to present these indicators with a single integral (synthetic) indicator which also takes into account the ratio between the economically active and the inactive population and its dynamics. Such an integral indicator was introduced for the first time by the author of this article in analyzing 
the differences in the development of the municipalities in Bulgaria. "This indicator is called Economically Active and Employed Population (EAEP) and is calculated using the following formula:

EAEP = (EC - EAC $)+(1$ - EIP / EAP $)$, where

- EC is the employment coefficient - the ratio (in \%) between the employed and the population of over $15 \mathrm{yrs}$ or the population in another age group;

- EAC is the economic activity coefficient the ratio (in \%) between the economically active population (employed and unemployed) and the population over 15 yrs of age or the population in another age group;

- EIP - economically inactive population of $15+$ yrs of age or in another age group (in number);

- EAP - the economically active population (in number), of $15+$ yrs or in another age group.

Theoretically, this indicator may have two extreme values (+ 1 and -99):

- When the whole $15+$ yrs population of a country or of one territorial unit is economically active and fully occupied, then the value of the EAEP indicator is equal to one, which is the most favorable situation;

- When the whole population aged over 15 yrs of a country or of a territorial unit is economically active but unemployed, ie the employment rate is zero, then the value of the EAEP indicator is minus 99, which is the most unfavorable situation;
- When the whole population of over $15 \mathrm{yrs}$ of a country or a territorial unit is economically inactive, then the value of the EAEP indicator does not make sense, it can not be determined because the economically active population is zero and zero can not be divided.

In the present article, the integral (synthetic) measure for a summarize assessment of the trends in the economic activity/ inactivity, employment and unemployment is first applied at national level. The values of this indicator by individual years are compared to a benchmark. This target value of the EAEP indicator is determined on the basis of parameters from the national targets in the Europe 2020 program, and specifically: economic activity coefficient $77.0 \%$, employment coefficient $75 \%$, economically active persons 3278.6 thousand people and economically inactive population 979.3 thousand people in the age group between 15 64 years. As a reserve for increasing the labor resources and the economically active persons, the following are considered: the reduction of the gray economy, the gradual increase of retirement age, the limitation of early retirement and disability pensions, the integration of immigrants, the increase of the economic activity by reducing the discouraged persons, including a higher level of participation of the Roma population.

The values of the EAEP indicator in the 15-64 age group for the period 2008 - 2018 are presented in Figure 1.

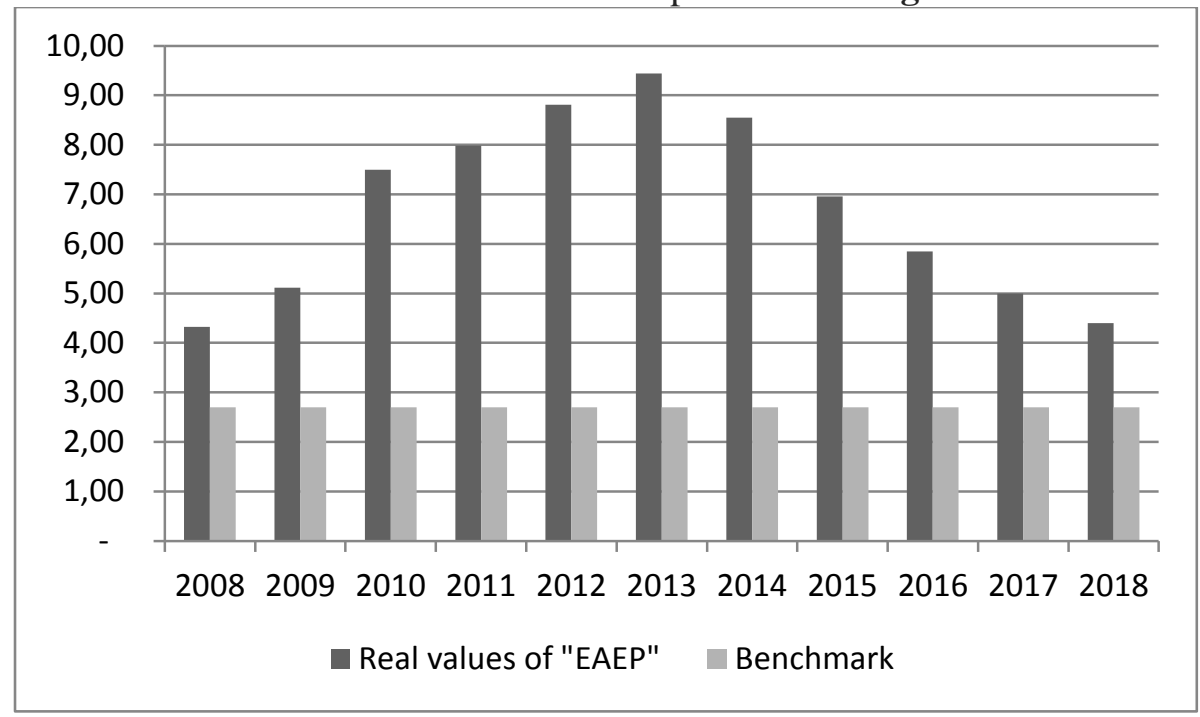

Figure 1. EAEP - 2008 - 2018 (age 15 - 64)

Source: Author's calculations based on data by the National Institute of Statistics - Labor Force Survey (2008 2018)

\footnotetext{
${ }^{1}$ Hristoskov, Y. Differences in the Development of the Municipalities in Bulgaria. Economic Studies, Year VIII, book 2, 1999 (p. 21 - 47).
} 
The dynamics of the EAEP indicator outline a trend of combined deterioration in its values after 2008 to 2013 and an improvement over the past 5 years. At the same time, the value of this indicator for Bulgaria, over the entire period, is much less favorable than the benchmark 2.70, calculated on the basis of the 2020 national target under Europe 2020.

The article also treats a modified version of the indicator labeled $E A E P_{(m)}$. The indicator was used by the author in a series of interim and annual reports for the Risk Management Laboratory of the New Bulgarian University. In this modified version, the indicator is calculated using the following formula:

$\operatorname{EAEP}(m)=(\operatorname{EAC}-$ EC $)+(\operatorname{EIP} /$ EAP $) * 100$,

Where: EAC - economic activity coefficient, EC - employment coefficient; EIP economically inactive population; EAP economically active population
HRISTOSKOV Y.

This modification is applied in order to obtain positive values across a wider range, especially when working with variation lines. In the ideal case, when all persons are economically active and occupied, the value of this indicator is 0 (zero), and the higher the values, the more unfavorable they are. When the economically inactive population is greater than the number of the economically active population, the $\mathrm{EAEP}_{(\mathrm{m})}$ indicator has values above 100 , which values are considered highly unfavorable. When the economically active persons are zero and, respectively, the coefficients of economic activity and employment are equal to zero, then the indicator can not be calculated (it is meaningless) because it can not be divided by zero.

Figure 2 presents the values of $\operatorname{EAEP}(\mathrm{m})$ in the 15-64 age group for the period 2008 2018.

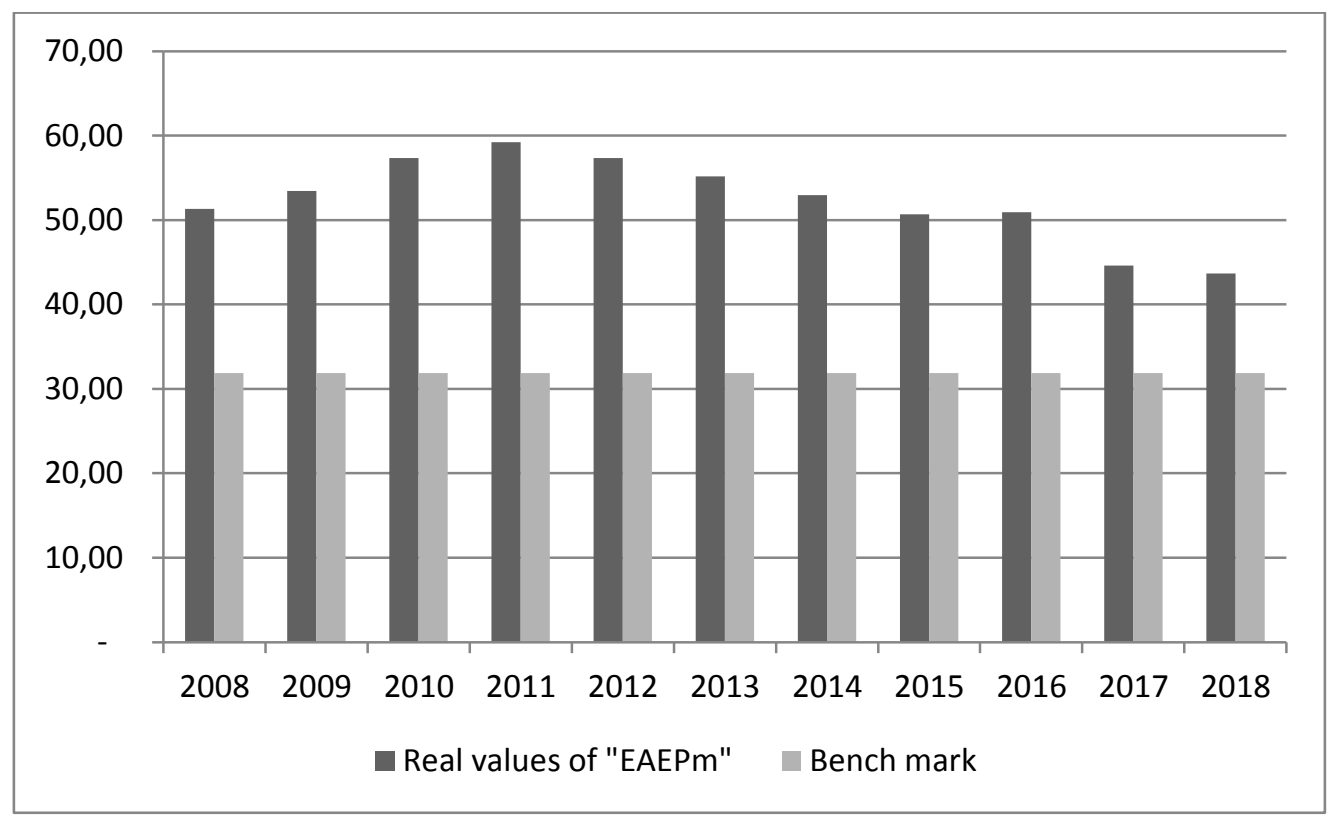

Figure 2. $\operatorname{EAEP}(\mathrm{m})$ - 2008 - 2018 (age 15 - 64)

Source: Author's calculations based on data by the National Institute of Statistics - Labor Force Survey (2008 2018)

The dynamics of the $\operatorname{EAEP}(\mathrm{m})$ indicator outline a trend of combined deterioration in its values after 2008 to 2016 and a significant improvement over the past 2 years. However, the value of this indicator for Bulgaria, over the entire period, is again less favorable than the benchmark 31.87 , calculated on the basis of the 2020 national target under Europe 2020.

Figure 3 shows the values by place of residence (city - village) and by statistical regions with population data of $15+$ years for
2018. The aim is to assess the collective impact of the economic activity/ inactivity and the employment with one integrated indicator and to compare the values of this indicator for cities and villages, and the individual regions, as well as their distancing from the country average. A target value was also set with the following parameters: EAC - 65\%, EC - 60, EAP (economically active population) - 3908 thousand people and EIP (population outside the workforce) of 2109 thousand people. 


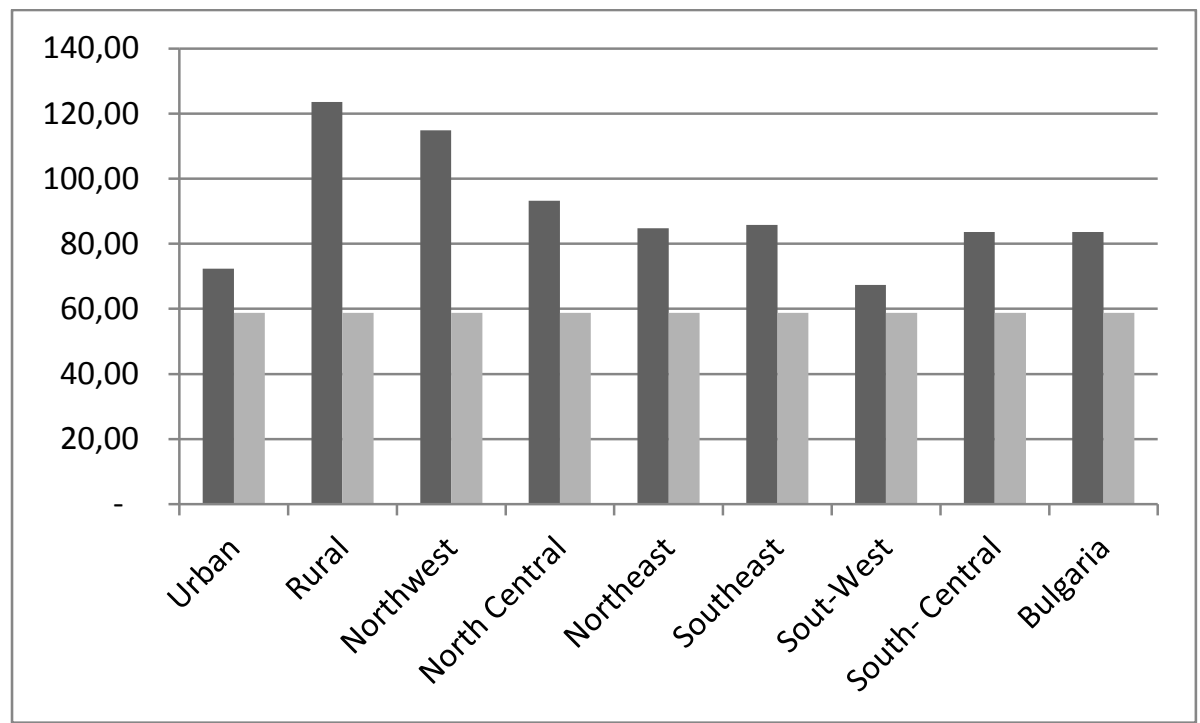

Figure 3. $\operatorname{EAEP}(\mathrm{m})$ - 2018 (age 15+)

Source: Author's calculations based on data by the National Institute of Statistics - Labor Force Survey 2018

It is clear from the graph that in the city-village dimension, the difference in the values of the $\operatorname{EAEP}_{(\mathrm{m})}$ indicator is 51 points. The reasons for these large fluctuations in the values of the indicator between cities and villages are the demographic depopulation, the high unemployment, the low educational level and the poor state of agriculture and its accompanying industries in the villages. By statistical regions, the most unfavorable values of the $\operatorname{EAEP}_{(\mathrm{m})}$ indicator are demonstrated in the Northwest (114.8) and the North Central Region (93.2). The most favorable and close to the target value by about 9 points is the South-West Region with a mark of 67.4, which includes the Sofia (capital) region. The other three regions have almost the same and close to the country's average value synthetic indicator. These values, however, differ by about 15 - 16 points from the set target value.

\section{CONCLUSION}

The empirical analysis of the trends in the economic activity, employment and unemployment reveals the following problem areas with risk and conflict potential:

- The positive trends of employment growth and the decrease of unemployment in the period 2017 - 2018 are the result of the increased economic activity mostly in the private sector and less as a result of the active labor market policy financed by the National Action Plan on Employment and the Operational Program for Human Resources Development. To some extent, the positive trend in employment is due to the declining number of people entering the labor market, given a much higher number of pensioners due to retirement. Within this positive trend, the issue of hiring vulnerable groups in the labor market (young people, people with disabilities, the long-term unemployed and representatives of the Roma community) remains partially resolved, which definitely hides a conflicting potential.

- The vast differences in employment and unemployment at regional level also bear conflicting potential. The latter is even higher at the level of administrative districts. The risk of social tensions in certain areas and regions can be avoided by linking social measures horizontally in the government program to measures in the field of economic, education and regional policy, a step which has not yet been made.

- The growing structural mismatches between the supply and demand of labor as a whole and their sharpest manifestations, encompassing the persistent shortage of certain qualification groups of specialists and the discrepancy between the quality of the educational product and the needs of the business are serious obstacles, not only for the currently operative companies, but for attracting new investors. The presence of such structural mismatches in the regions with the highest unemployment and poverty is condemning them to a continuous lag, thus sharpening the regional dimension of the conflicts.

The conclusion drawn from the analysis shows that there is a risk of failure to meet one of the Europe 2020 national targets, namely a $76 \%$ employment rate for men and women in the 20-64 age group. There is also a risk of human capital erosion and a further lagging behind in the economic activity, employment and unemployment in the Northwest and the North Central Region. To address this risk, both general and specific for the separate regions coordinated policies on demography, education, health and social services are required. 